\title{
Antimicrobial Drug Discovery: Evident Shifting from Terrestrial to Marine Micro-organisms
}

\author{
R.D. Singh*, S.K. Mody, H.B. Patel, Sarita Devi, V.N. Sarvaiya, \\ H.A. Patel and B.R. Patel
}

\author{
Department of Pharmacology and Toxicology, CoVSc and AH, SDAU, \\ Sardarkrushinagar, Gujarat -385506, India \\ *Corresponding author
}

\begin{tabular}{|c|c|}
\hline & A B S T R A C T \\
\hline Keywords & \multirow{4}{*}{$\begin{array}{l}\text { Marine derived micro-organisms secrete precious bioactive molecules in } \\
\text { traceable amount as their secondary metabolites. These bio-molecules can } \\
\text { be developed into antimicrobial agents, using modern tools of molecular } \\
\text { biology and drug discovery. Exhaustion of terrestrial sources and demand } \\
\text { of newer class of antibiotics due to ever-increasing resistance level in } \\
\text { existing antimicrobial drugs, led a paradigm shift from land to ocean for } \\
\text { discoveries of such agents. Marine bacteria, fungi and algae are potential } \\
\text { sources of novel antimicrobial drugs. Many such agents are identified } \\
\text { worldwide including India. Huge cost of marine bioprospecting and non- } \\
\text { culturability of marine microbes are the major hurdles in marine drug } \\
\text { development which emphasized need of public-private partnerships and } \\
\text { advanced technologies like metagenomic tools, genetic recombinant } \\
\text { techniques and chemoenzymatic synthesis. }\end{array}$} \\
\hline $\begin{array}{l}\text { Antimicrobial } \\
\text { drugs, } \\
\text { Marine } \\
\text { bioprospecting, } \\
\text { Marine drug } \\
\text { discovery, } \\
\text { Micro-organisms. }\end{array}$ & \\
\hline Article Info & \\
\hline $\begin{array}{l}\text { Accepted: } \\
\text { 25 April } 2017 \\
\text { Available Online: } \\
10 \text { May } 2017\end{array}$ & \\
\hline
\end{tabular}

\section{Introduction}

Ocean, the mother of origin of life, covers over $70 \%$ of the earth's surface and hosts approximately $87 \%$ of the Earth's life (Hu et al., 2011). Marine wealth is aptly described as 'blue gold'. More than 2.30 lakhs marine species and isolation of more than 28,000 structurally unique bioactive compounds have been documented till now. Sponges (37\%), coelenterates $(21 \%)$ and microorganisms $(18 \%)$ are the three major sources of biomedical compounds (Blunt et al., 2004). Marine life is the source of unique chemical compounds which are accumulated in living organisms as secondary metabolites, a chemical compound produced by an organism which is not required for survival of the organism but presumably confers an evolutionary advantage like performing defence, communication signalling or reproductive functions. These bioactive molecules may be convertible to antimicrobial drugs using modern tools of molecular biology and advanced technology. Some of these molecules are identified as 'lead' compounds which are undergoing various phases of clinical trial and thus have the 
prospect of being new pharmaceutical products (Murti and Agrawal, 2010). Researchers have extensively focused on marine originated antimicrobial drugs, looking at the fact that terrestrial source of antibiotics are exhausted and demand of newer class of antimicrobials due to ever increasing resistance level in existing drug classes. Antibiotics like antibacterial, antiviral, antifungal agents are among the pharmaceutical agents being developed from marine resources (Mayer and Hamann, 2002).

\section{Chemical diversity in marine micro- organisms}

Marine microorganisms have more chemical diversity as they evolved over a long period of time in severe and hostile marine environmental conditions like freezing temperatures, high pressures, intense heat from hydrothermal vents and perpetual darkness due to lack of sunlight (Ruth, 2006 and Synnes, 2007). The extensive variability in marine environment in terms of temperature, pressure, type of nutrients available and light intensity has facilitated extensive speciation at all phylogenetic levels, from microorganisms to mammals (Jha and Zi-rong, 2004). Two thumb rules can be considered for marine biodiversity i.e. 'high biodiversity means high chemical diversity' and 'habitat diversity equates to chemical diversity'. The marine natural products are divided into seven classes based on their chemical structure: terpenoids, steroids (including steroidal saponins), alkaloids, ethers (including ketals), phenols (including quinones), strigolactones, and peptides ( $\mathrm{Hu}$ et al., 2011). According to MarnLit website, marine exploration has resulted in the isolation of more than 20,000 structurally unique bioactive marine natural products (MNPs). The annual discovery of marine natural products remained at a constant level of about 500 products in the late 1990s but this number has increased from 600 to over 1000 compounds from 2008 to 2010, a significant increase which was partly driven by new developments in modern analytical technology and instruments, especially the development of the high resolution nuclear magnetic resonance spectrometer (NMR) and mass spectrometry (MS) coupled with highperformance LC and GC (Hu et al., 2011 and Mehbub et al., 2014).

\section{Marine micro-organisms}

As a source of promising antimicrobial drugs, marine micro-organisms can be divided into three categories i.e. marine bacteria, fungi and sea-weeds. Marine bacteria are capable of producing unusual bioactive compounds that are not observed in terrestrial sources (Fenical, 1993). Marine bacteria (and fungi also) are of great interest as novel and rich sources of biologically active products. They live in close association with soft-bodied marine organisms, which lack obvious structural defence mechanisms, and thus rely on chemical defence by production of bioactive secondary metabolites, either by themselves or by associated microflora, to survive in their extreme habitat (Jensen and Fenical, 1994). Fungi appear to be rare in marine environments. Marine fungi live in estuarine environments (transition zone between sea and river). Many small, usually one-celled fungi live in seawater, almost all belonging to the Phycomycetes. They are found particularly in the vicinity of the coast, up to 2000 spores per liter water. Algae, sponges and mangroves have special interactions with fungi and are the most common materials for the isolation of fungal strains that can produce antibacterial or antifungal compounds. The marine fungal strains from Hypocreales (order), and the Aspergillus and Penicillium genera should be utilized more for the discovery of new antibacterial or antifungal compounds (Xu et 
al., 2015). Seaweed (macroalgae) refers to several species of macroscopic, multicellular, marine algae, found mostly at sea bed. The term includes red, brown, and green algae. Seaweeds are abundant in the intertidal zones and in clear tropical waters. Marine algae have received comparatively less bioassay attention.

\section{Marine bio-prospecting for microbes}

Exploring marine micro-organisms for discovery of possible drug candidate biomolecules requires different strategies for different strata of marine environment based on depth or sea-level. The difficulty in the search of metabolites from marine bacteria is mainly due to the non-culturability of the majority (Hugenholtz and Pace, 1996). Researchers are developing new technology that allows them to cultivate microbes found above sea level that couldn't previously be grown in the laboratory. Many symbiotic bacteria are habitated at 200 metres below sea level. Many species of sponge possess symbiotic bacteria. A whole new bacterial phylum, Entotheonella, was characterized in 2014 and identified as the producer of almost all the polyketides and peptides associated with the marine sponge host, Theonella swinhoei. As the ocean gets deeper i.e. 1,000 metres below sea level, the light disappears, microbes become dependent on chemosynthesis, rather than photosynthesis, for energy. For researchers, these microbes are a source of rich chemical diversity and novel chemical pathways. It is estimated that below 3,000 meters, each sample collected is $50 \%$ likely to contain a species new to science (Lawrence, 2015).

\section{Need of marine derived antimicrobial agents}

As serious infectious diseases and multidrug resistance are emerging repeatedly, novel antimicrobials are needed considerately to combat these bacterial pathogens, but the progress of discovery seems relatively slow. Most chemical scaffolds of antibiotics used now were just introduced between the mid1930s and the early 1960s. One of the main reasons for innovation gap, exists for discovery of antibacterial drugs between years 1962 to 2000, is exhaustion of cultivable terrestrial microbes (Fischbach and Walsh, 2009). To summarize, need of novel antimicrobials is due to resistance of the existing drugs, exhaustion of terrestrial bioprospecting and quest for novel scaffolds for antimicrobial drugs. In past, easy-to-find antibiotics are discovered but scientists have to work harder and think more cleverly to find new drugs. Moreover, to confiscate lack of enthusiasm in antibacterial discovery owing to commercial reasons like poor return, it is most important to delink research and development costs from drug pricing and the return from investment on antibacterial discovery (Braine, 2011). Compared to the terrestrial environment, the ocean remains an underexplored habitat with unparalleled biodiversity, leaving it the most promising place to yield new antibacterial metabolites (Yanling et al., 2013).

\section{Promising antimicrobial agents derived from marine microorganisms}

Historically, Brotzu isolated a fungus from the sea near a sewage outfall in Sardinia in 1945. He used an extract of this for the parenteral treatment of patients suffering from typhoid fever and from infection with Brucella melitensis, and appears to have achieved some success. A culture of the organism was received in Oxford, where seven antibiotic substances were isolated from it. One of these was cephalosporin $\mathrm{C}$, of which 7-aminocephalosporanic acid is the nucleus (Murdoch et al., 1964). Later on cephalosporin drugs were developed from this compound. 
New antibacterial agents with novelty and/or complexity in chemical structure derived from marine bacteria have been elaborated clearly (Hughes and Fenical, 2010 and Rahman et al., 2010). Scientists have reported the discovery of various antibiotics from marine bacteria (aplasmomycin, himalomycins, and pelagiomycins), algae (cycloeudesmol, aeroplysinin-1(+), prepacifenol and tetrabromoheptanone), and actinomycetes (marinomycins C and D) (Doshi et al., 2011). The antibacterial and antifungal compounds from marine fungi have quickly increased since 2010, and marine fungi have been an important source of antibacterial and antifungal compounds eg. Isaridinscyclohexadepsipeptides, Cristatumins indole-alkaloids, sesquiterpenoids (antibacterials), Trichoderins (antimycobacterial activity),

Penicisteroid A (antifungal) etc. The dominant genera in the marine fungi producing antimicrobial compounds were the Aspergillus genus and the Penicillium genus (Xu et al., 2015). Some other potent antimicrobials agents have been derived from marine resource but from other than microorganisms like sponge-derived polydiscamide and darwinolide (Rajanbabu et al., 2015 and Von salm et al., 2016).

\section{Progress in India}

India, blessed with coastline of about 7517 $\mathrm{km}$ and vast marine biodiversity, has great prospect in discovery of unexplored marine source of drugs (Saravanan and Debnath, 2013). Scientists from Indian Institute of Chemical Biology, Calcutta have isolated an active antimicrobial compound from a microorganism which is a lipid and shows very strong activity against bacteria and fungi including several that are multiple drug resistant such as S. aureus (strain 23602), E. coli (strain DH50), Aspergillus niger (strain MTCC 1344) (Saha et al., 2005).
In a study at National Institute of Oceanography, CSIR, Goa, an antibiotic compound containing an indole and a diketopiperazine moiety was isolated from the culture medium of Penicillium chrysogenum, (MTCC 5108), an endophytic fungus on the mangrove plant Porteresia coarctata (Roxb.). The cell free culture medium of $P$. chrysogenum showed significant activity against Vibrio cholerae, (MCM B-322), a pathogen causing cholera in humans. Its antibacterial activity was comparable with standard antibiotic, streptomycin (Devi et al., 2012).

A total of 26 actinobacterial strains were isolated from the marine sediments collected from various sites of Port Blair Bay, Andaman and Nicobar Islands, where no collection has been characterized previously. Majority of the isolates exhibited substantial antibacterial activity against human pathogens. Out of 26 isolates, 96\% exhibited appreciable inhibitory activity against Gram negative bacteria, $73 \%$ acted against Gram positive bacteria and $23 \%$ revealed excellent antibacterial activity against both Gram positive and Gram negative bacteria. Strain Streptomyces sp. NIOTVKKMA02 was found to have broad spectral antibacterial activity (Meena et al., 2013).

Scientists at the National Institute for Research in Tuberculosis, Chennai, and IITM, Periyar University, Salem, extracted and studied the biological activity of molecule, Transitmycin. It was derived from the marine microorganism Streptomyces $\mathrm{sp}$. isolated from a soil sample of the Rameswaram coral reef. In January 2014, ICMR filed a patent on transitmycin in WIPO (WIPO, 2015) entitled 'A compound, transitmycin, effective against bacterial and viral pathogens'. In the patent, it is claimed that compound of the invention is effective against bacterial pathogens such as Mycobacterium tuberculosis, Bacillus subtilis, Bacillus pumilus, Bacillus cereus, 
Staphylococcus aureus, and Acinetobacter baumanii. The compound was claimed to be found effective against multiple drug resistant and extensively drug resistant strains of Mycobacterium tuberculosis.

\section{Challenges and solutions in marine bio- prospecting}

There are many challenges too in marine bioprospecting mainly including high exploration cost, problem of supply, threat to marine biodiversity, standardization of a commercial product, legal issues related rights (IPRs) etc. The difficulty in the Marine bio-prospecting or search of metabolites from marine bacteria is mainly due to the non-culturability of the majority (over 99\%). Marine bio-prospecting is typically associated with public-private partnerships, due to the astronomical expenses, state of the art technology and specialized expertise associated with marine exploration. It is estimated that marine exploration costs at least $\$ 30000$ per day and $\$ 1$ million for 30 days, (Ruth, 2006) expenditure well beyond the means of public institutions. Destruction of the marine environment and/or local extinction of species due to bio-prospecting would be inevitable consequences. However, other alternatives or new experimental approaches, such as metagenomic tools, genetic recombinant techniques and chemoenzymatic synthesis have been mentioned as a possible solution to such problems (Pomponi, 1999; Cragg and Newman, 2001; Hunt and Vincent, 2006).

\section{References}

Blunt, J.W., Copp, B.R., Munro, M.H.G., Northcote, P.T. and Prinsep, M.R. 2004. Marine Natural Products. Nat. Prod. Rep., 21: $1-49$.

Braine, T. 2011. Race against time to develop new antibiotics. Bull. World Health Organ., 89(2): 88-89.

Cragg, G.M. and Newman, D.J. 2001. Natural product drug discovery in the next millennium. Pharm. Biol., 39: 8-17.
Devi, P., Rodrigues, C., Naik, C.G. and D'Souza, L. 2012. Isolation and characterization of antibacterial compound from a mangroveendophytic fungus, Penicillium chrysogenum MTCC 5108. Indian $J$. Microbiol., 52(4): 617-623.

Doshi, G.M., Aggarwal, G.V., Martis, E.A. and Shanbhag P.P. 2011. Novel Antibiotics from Marine Sources. Indian J. Pharm. Sci. Nanotech., 4(3):1446-1461.

Fenical, W. 1993. Chemical studies of marine bacteria: developing a new resource. Chem. Rev., 93(5): 1673-1683.

Fischbach, M.A. and Walsh, C.T. 2009. Antibiotics for emerging pathogens. Sci., 325(5944):1089-1093.

Hu, G.P., Yuan, J., Sun, L., She, Z.G., Wu, J.H., Lan, X.J., Zhu, X., Lin, Y.C. and Chen, S.P. 2011. Statistical research on marine natural products based on data obtained between 1985 and 2008. Mar. Drugs, 9(4): 514-525.

Hugenholtz, P. and Pace, N. R. 1996. Identifying microbial diversity in natural environment: a molecular phylogenetic approach. Trends Biotechnol., 14:190-197.

Hughes, C.C. and Fenical, W. 2010. Antibacterials from the sea. Chem., 16(42): 12512-12525.

Hunt, B. and Vincent, A.C.J. 2006. Scale and sustainability of marine bioprospecting for pharmaceuticals. AMBIO: J. Human Environ., 35: 57-64.

Jensen, P.R., and Fenical, W. 1994. Strategies for the discovery of secondary metabolites from marine bacteria: ecological perspectives. Annu. Rev. Microbiol., 48: 559-584.

Jha, R.K. and Zi-rong, X. 2004. Biomedical Compounds from Marine organisms. Mar. Drugs, 2: 123-146.

Lawrence, J. 2015. Drug discovery returns to the wild: Finding novel natural products. Pharm. J., 294(7849), online URI: 20067820.

Mayer, A.M. and Hamann, M.T. 2002. Marine pharmacology in 1999: compounds with antibacterial, anticoagulant, antifungal, anthelmintic, anti-inflammatory, antiplatelet, antiprotozoal and antiviral activities affecting the cardiovascular, endocrine, immune and nervous systems, 
and other miscellaneous mechanisms of action. Compar. Biochem. Physiol. Part C: Toxicol. Pharmacol., 132(3): 315-339.

Meena, B., Rajan, L.A., Vinithkumar, N.V. and Kirubagaran, R. 2013. Novel marine actinobacteria from emerald Andaman and Nicobar Islands: a prospective source for industrial and pharmaceutical by products. BMC Microbiol., 13(1): 145.

Mehbub, M. F., Lei, J., Franco, C. and Zhang, W. 2014. Marine sponge derived natural products between 2001 and 2010: Trends and opportunities for discovery of bioactives. Mar. Drugs, 12(8): 4539-4577.

Murdoch, J.M., Speirs, C.F., Geddes, A.M. and Wallace, E.T. 1964. Clinical trial of cephaloridine (Ceporin), a new broadspectrum antibiotic derived from cephalosporin C. British Med. J., 2(5419): 1238-1240.

Murti, Y. and Agrawal, T. 2010. Marine derived pharmaceuticals - Development of natural health products from marine biodiversity. Int. J. Chem. Tech. Res. 2(4): 2198-2217.

Pomponi, S.A. 1999. The bioprocesstechnological potential of the sea. $J$. Biotechnol., 70(1): 5-13.

Rahman, H., Austin, B., Mitchell, W.J., Morris, P.C., Jamieson, D.J., Adams, D.R., Spragg, A.M. and Schweizer, M. 2010. Novel antiinfective compounds from marine bacteria. Mar. Drugs, 8(3): 498-518.

Rajanbabu, V., Chen, J. Y. and Wu, J. L. 2015. Antimicrobial Peptides from Marine Organisms. In: Handbook of Marine Biotechnology. Springer Berlin Heidelberg. pp. 747-758.

Ruth, L. 2006. Gambling in the deep sea. EMBO., 7(1): 18 .
Saha, M., Ghosh, D. Jr., Ghosh, D., Garai, D., Jaisankar, P., Sarkar, K.K., Dutta, P.K., Das, S., Jha, T. and Mukherjee, J. 2005. Studies on the production and purification of an antimicrobial compound and taxonomy of the producer isolated from the marine environment of the Sundarbans. Appl. Microbiol. Biotechnol., 66(5): 497505.

Saravanan, A. and Debnath, D. 2013. Patenting trends in marine biodiversity: Issues and Challenges. Pharm. Utility., 7(4): 1-13.

Synnes, M. 2007. Bioprospecting of organisms from the deep sea: scientific and environmental aspects. Clean Technol. Environ. Policy, 9: 53-56.

Von Salm, J.L., Witowski, C.G., Fleeman, R. M., McClintock, J.B., Amsler, C.D., Shaw, L. N., and Baker, B.J. 2016. Darwinolide, a new diterpene scaffold that inhibits methicillin-resistant Staphylococcus aureus biofilm from the Antarctic sponge Dendrilla membranosa. Org. Lett., 18(11): 2596.

WIPO. 2015. A compound, transitmycin, effective against bacterial and viral pathogens. Patent Application no. WO 2015022698 A1. Available online at official website of World Intellectual Property Organization. URL:

https://patentscope.wipo.int/search/en/ detail.jsf?docId =WO2015022698.

Xu, L., Meng, W., Cao, C., Wang, J., Shan, W. and Wang, Q. 2015. Antibacterial and Antifungal Compounds from Marine Fungi. Mar. Drugs, 13(6): 3479-3513.

Yanling, J., Xin, L. and Zhiyuan, L. 2013. The Antibacterial Drug Discovery, In: Drug Discovery, On-line edition, Intech, pp. 289307.

\section{How to cite this article:}

Singh R.D., S.K. Mody, H.B. Patel, Sarita Devi, V.N. Sarvaiya, H.A. Patel and Patel B.R. 2017. Antimicrobial Drug Discovery: Evident Shifting from Terrestrial to Marine Micro-organisms. Int.J.Curr.Microbiol.App.Sci. 6(5): 2322-2327. doi: https://doi.org/10.20546/ijcmas.2017.605.259 